\title{
EVALUATION OF INDUCED SPUTUM CYTOLOGY IN ASTHMATIC CHILDREN
}

\author{
Debora Carla Chong-Silva ${ }^{1}$, Adriana Nascimento ${ }^{1}$, Roberta Cunha ${ }^{1}$, Elessandra \\ Bitencourt $^{1}$, Leticia Botelho ${ }^{1}$, Ana Beatriz Dantas ${ }^{1}$, Cristine Rosario ${ }^{1}$, Carlos Riedi ${ }^{2}$, \\ Herberto Chong-Neto ${ }^{1}$, Denise Eli ${ }^{1}$, and Nelson Rosario Filho ${ }^{3}$ \\ ${ }^{1}$ Federal University of Parana \\ ${ }^{2}$ Federal University Parana \\ ${ }^{3}$ Universidade Federal do Paraná
}

February 3, 2021

\begin{abstract}
Objective: To evaluate the viability of sputum cytology in asthmatic children, recognizing inflammatory patterns and correlating them with clinical, epidemiological and functional variables of the disease. Methods: This was a cross-sectional and observational study of children with asthma who underwent sputum induction through increasing concentrations of nebulized hypertonic saline solution from $3 \%$ to $7 \%$. The samples were processed according to the technique developed by Pizzichini et al. and the cytological pattern classified as pauci-granulocytic, neutrophilic, eosinophilic and mixed. Samples with cell viability $>50 \%$ were considered adequate. Asthma control was assessed using the asthma control test (ACT). Results: Seventy-nine children performed sputum induction. Thirty-three samples were excluded because they were not viable for analysis, resulting in 46 samples. The children's average age was $9.4( \pm 3)$ years. There was a predominance of eosinophilic $(25 / 46,54.3 \%)$, followed by mixed $(13 / 46,28.3 \%)$, pauci-granulocytic $(7 / 46,15.2 \%)$ and neutrophilic $(1 / 46,2.2 \%)$ pattern. Sixty-three percent of the children had severe asthma and $84.7 \%$ were treated with inhaled corticosteroids. The ACT showed that $25(56.8 \%)$ patients had the disease under control. Forty-five children (97.8\%) underwent pulmonary function tests (spirometry) and in 13 cases (28.9\%) an obstructive ventilatory defect was found. Conclusions: The eosinophilic profile was predominant in the assessed asthmatic children. Non-eosinophilic phenotypes were found, but less frequently. There was no difference between the clinical variables and the sputum profile in this study group. Sputum induction in children with asthma is feasible and safe and can contribute to a specific and personalized approach to the disease.
\end{abstract}

\section{INTRODUCTION}

Asthma is a heterogeneous disease that affects both children and adults, with children prevalence that ranges from $4 \%$ to $30 \%$ in Latin America ${ }^{1}$. Despite little information on the impact of asthma in developing countries, approximately 130,000 asthma-related hospitalizations and a rate of 5 deaths/day were estimated in Brazil in $2013^{1}$.

The clinical presentation is characterized by common symptoms such as cough and wheezing, and physiologically with varying degrees of airflow limitation. Typically, these changes occur in association with airway inflammation and remodeling. In children, the mechanisms involved in wheezing are distinct, and some phenotypes may be established from age at onset, presence of atopy, and triggered by viral infections. Approximately one-third of wheezing children will remain symptomatic in adulthood, and factors such as allergic sensitization and smoking increase the chance of its persistence ${ }^{2}$.

In recent decades, precision medicine has been used to better characterize asthma phenotypes, thus establishing treatment alternatives for patients with severe refractory asthma, which is the real challenge for 
pulmonologists. Clustering is based on clinical characteristics associated with complementary research, resulting in phenotypes such as early onset allergic asthma or late onset asthma ${ }^{3}$. However, within a given phenotype, distinct pathophysiological mechanisms may be involved, even in a group of patients with similar clinical presentation. This last concept brings what is now understood as endotype, meaning knowledge at a more specific cellular and immunological level ${ }^{3}$.

Sputum cytological analysis is cited as a safe and promising technique that evaluates the cellularity present in the lower airway mucosa and can be classified into four main cellular patterns: eosinophilic, neutrophilic, mixed, and pauci-granulocytic. However, there is some heterogeneity of these patterns among patients and their correlation with clinical progression and inhaled corticosteroid treatment response is still a challenge ${ }^{4}$.

Thus, the objective of this study was to evaluate the feasibility of sputum cytology in children with asthma by recognizing inflammatory patterns. The secondary objectives were to correlate cytological patterns with clinical, epidemiological, and functional disease variables.

\section{METHODS}

This was a cross-sectional observational study through the analysis of a spreadsheet containing data collected from asthma outpatient charts in a tertiary hospital. Stable asthmatics collected sputum from March 2018 to April 2020, once they met the sample viability criteria for analysis. The sociodemographic data, past and family history, skin allergy test (prick test), total serum IgE levels, blood eosinophil count, spirometry values and induced-sputum cytology of these patients were analyzed. The laboratory results used were those collected closest to the sputum collection date.

Asthma severity was classified according to the National Asthma Education and Prevention Program (NAEP) as mild, moderate, or severe ${ }^{5}$. Peripheral blood eosinophilia were considered when eosinophils count were above $400 \times 10^{3} / \mathrm{uL}$ and total serum $\mathrm{IgE}$ was above $100 \mathrm{IU} / \mathrm{mL}^{6}$. Prick test was routinely performed in asthmatics. The tested allergens were Dermatophagoides pteronyssinus, Blomia tropicalis, Blatella germanica, Canis familiaris, Felis domesticus, Lolium multiflorum, in addition to a positive control (histamine $10 \mathrm{mg} / \mathrm{mL}$ ), and negative control (saline $0.9 \%$ ). Tests were considered positive in the presence of a wheal with diameter [?]3 $\mathrm{mm}$ and a negative control (normal saline). Sputum collection and examination were performed as previously described by Pizzichini et al. ${ }^{7}$. Briefly, the sputum was separated from contaminating saliva. A mixture of sputum and dithiothreitol solution was vortexed for $15 \mathrm{~min}$, and four volumes of Dulbecco's PBS were added. The suspension was then filtered through 48-mm nylon gauze (Millipore Corporate Headquarters, Billerica, MA, USA) and centrifuged at $314 \mathrm{xg}$ for $10 \mathrm{~min}$. Cell viability was determined by trypan blue exclusion. The cytospin slides prepared after cytocentrifugation were stained with

May-Grunwald-Giemsa to determine the differential cell count. Samples with up to $20 \%$ epithelial cells and more than $50 \%$ viability were considered adequate for analysis ${ }^{7}$. The differential counts in sputum were classified into one of the following standards: eosinophilic (eosinophils $>2.5 \%$ and neutrophils [?] $54 \%$ ), neutrophilic (eosinophils [?]2.5\% and neutrophils $>54 \%$ ), mixed (eosinophils $>2.5 \%$ and neutrophils $>54 \%$ ), and pauci-granulocytic (eosinophils $<2.5 \%$ and neutrophils $<54 \%)^{8}$.

From spirometry results, forced expiratory volume value in the first second (FEV1) was considered normal if $>80 \%$ predicted for age. In addition, patients with a ratio of forced expiratory volume in the first second to forced vital capacity $(\mathrm{FEV} 1 / \mathrm{FVC})<0.9$ were diagnosed with obstructive ventilatory defect. The response to inhaled salbutamol $(400 \mathrm{mcg})$ was considered positive when FEV1 increased more than $12 \%$ of the baseline value $^{9}$.

Patients responded to the asthma control test (ACT) questionnaire, and a score of [?]20 characterized controlled asthma ${ }^{10,11}$.

Continuous variables are expressed as means, standard deviation, median, and maximum and minimum values. The categorical variables (comparisons of cytological profiles with clinical, epidemiological, and functional variables) were analyzed using the Fisher's exact test and considered significant when p-value $<0.05$. 
The study protocol was approved by the Ethics and Research Committee of Hospital de Clinicas, Federal University of Parana (CAAE: 29628220.4.0000.0096).

\section{RESULTS}

From April 2018 to March 2020, seventy-nine asthmatic patients underwent the induction of sputum. No patient had to interrupt the collection due to adverse events (dyspnea, wheezing, or change in peak expiratory flow rate). Thirty-three cases were excluded due to sputum sample inadequacy that resulted in 46 patients completely studied of whom $27 / 46(58.7 \%)$ were male and $19(41.3 \%)$ were female. The mean age was 9.4 (+-3) years.

Asthma was severe in $29(63.1 \%)$ and moderate in $17(36.9 \%)$ patients. No patient was classified as having mild asthma. Thirty-nine (84.7\%) patients were on regular inhaled steroids. ACT showed that $25(56.8 \%)$ children had controlled disease.

The mean age at the first asthma attack was $3.2(+-3.3)$ years, and $12(26 \%)$ children presented the crisis before the first year of life. In addition, $44(95.6 \%)$ patients had already needed emergency department visit at least once, $17(36.9 \%)$ needed hospitalization and five (10.8\%) needed admission to intensive care unit. The most common allergic comorbidity was rhinitis, observed in 44 (95.6\%) patients, followed by conjunctivitis in $13(28.2 \%)$ and atopic dermatitis in $11(23.9 \%)$ patients. Family history of asthma was present in $30(65.7 \%)$ patients, and $16(34.7 \%)$ lived with smoker at home.

Allergy skin tests performed in $41(89.1 \%)$ patients were positive in $35(85.4 \%)$, in $24(68.5 \%)$ for only one inhalant allergen (mono-sensitization). Sensitization to mites predominated and was present in all tested patients.

The median total serum IgE levels was $797 \mathrm{IU} / \mathrm{mL}(0-9,411)$ and considered elevated in 29/35 (82.8\%) patients. The median blood eosinophil count was $505 \times 103 / \mathrm{uL}(0-2,094)$ and abnormally elevated in 24/36 $(66.6 \%)$.

Spirometry was performed in 45 children $(97.8 \%)$, and $13(28.9 \%)$ showed obstructive ventilatory defect. The bronchodilator response was positive in $19(42.2 \%)$ patients. Table 1 shows the characteristics of the study sample.

A predominance of eosinophilic pattern has been found in induced-sputum $(25 / 46,54.3 \%)$, followed by mixed (13/46 - 28.3\%), pauci-granulocytic $(7 / 46-15.2 \%)$, and neutrophilic $(1 / 46,2.2 \%)$ patterns.

There was no statistically significant correlation between the four cytological profiles and clinical, laboratory, and functional variables. However, if samples were sub-grouped in eosinophilic (eosinophilic and mixed) and non-eosinophilic (neutrophilic and pauci-granulocytic) patterns, there was an association between elevated blood eosinophils and the sputum eosinophilic pattern $(\mathrm{p}=0.02)$. Table 2 .

\section{DISCUSSION}

The present study expands the perspectives in the therapeutic follow-up of children with asthma, mainly in reference centers. Few studies have been published on the subject in in children in this age group.

. The sample size was adequate and the success rate was $58 \%$, comparable to that of similar studies, since it is a specific population, reflecting a good applicability of the method to the pediatric population ${ }^{12}$. In addition, the method proved to be safe. No patient had adverse events or had to interrupt the procedure. Bronchospasm was not observed during the procedure, even in the case of an asthmatic population. Proven safety of the procedure and the incorporation into the routine of the investigation of children with asthma in our center, there was an increase in the number of viable samples, when compared to the beginning of the study execution.

There was a predominance of children with severe asthma in the study population. Justified by the fact that the study was conducted in a tertiary hospital that serves patients of greater complexity and is a reference for primary health care services in the region. 
The predominance of the eosinophilic pattern in the sputum pattern (54\%) was expected and has already been described in other studies, mainly in children, who frequently present the allergic phenotype. Eosinophils are the main inflammatory cells in the pathogenesis of asthma, especially in atopic patients, who generally have a profile of Th2 cytokines, represented by IL-4, IL-5 and IL-13, blood eosinophilia and increased total $\operatorname{IgE}{ }^{13,14}$.

Another important finding in this study was the positive correlation between sputum and blood eosinophil counts. Although some studies do not show this correlation, this correspondence is interesting since the collection of peripheral blood is easier and more accessible when compared to sputum induction and could be used to guide and monitor the treatment of childhood asthma. Further studies are needed to clarify this association $^{15,16,17}$.

The considerable frequency of non-eosinophilic phenotypes (neutrophilic and pauci-granulocytic) is noteworthy in these asthmatic patients ( $43.5 \%$ of the sample).

Sputum neutrophilia is related to severe asthma in adults, resistant to treatment with inhaled corticosteroids and less related to atopy ${ }^{4}$. In pediatrics, several hypotheses about the presence of neutrophils in sputum have been formulated, including the greater occurrence of viral infections, which are known to generate neutrophilic inflammation. Sputum is not routinely analyzed in children with acute respiratory symptoms, which could elucidate the finding and to avoid bias. Another hypothesis suggested would be that there would be an increase in neutrophils in the bronchial mucosa in response to treatment with corticosteroids inhaled by chemotaxis and inhibition of apoptosis of these cells in sputum ${ }^{18,19}$. In view of this, an initial eosinophilic pattern could hypothetically become mixed with treatment with inhaled corticosteroids. In this study, there was no significant difference between sputum cytological profiles and children's inhalation treatment, but the cross-sectional character of the study is a limitation. In a longitudinal study evaluating treatmentresistant pediatric patients with severe asthma, Eller et al. reported a greater number of eosinophils in the initial induced sputum of patients who obtained better control of asthma, with a tendency to become pauci-granulocytic in the final sample ${ }^{20}$. The authors showed that the presence of neutrophils was higher in the sputum of children with uncontrolled asthma ${ }^{20}$. In this study group there was a predominance of the eosinophilic pattern even in children using inhaled corticosteroids as well as children with non-eosinophilic sputum pattern were not all in the uncontrolled asthma group. The follow-up, with serial sputum evaluations of the same patient, may clarify this question.

Allergic comorbidities were prevalent in the studied group, with percentages of rhinitis and atopic dermatitis similar to those of two other studies developed in Brazil ${ }^{21,22,23}$. Almost all asthmatics evaluated had allergic rhinitis, drawing attention to this frequent association ${ }^{23}$. This atopic profile was confirmed by a high frequency of total $\mathrm{IgE}$ above normal and peripheral eosinophilia in the study population.

Most patients (85\%) were sensitized, especially to household dust mites, again confirming the atopic profile of the population and according to data published from other Brazilian cities ${ }^{24,25,26}$. In the case of children with moderate to severe illness, recommendations to avoid exposure to these allergens should be emphasized at each visit.

Lung function was normal in most patients, despite having clinically moderate or severe asthma, uncontrolled in $43.2 \%$ of cases. Previous studies have already pointed out that the findings of spirometry may not be faithfully related to the severity of childhood illness and that clinical parameters are the most useful for conducting treatment in this age group ${ }^{27}$. However, the role of spirometry in the management of asthma is well established, since it is useful to identify patients at higher risk due to the presence of obstructive ventilation defect and a positive response to bronchodilator ${ }^{28}$. This response in patients with normal spirometry is an alert to specialists and may represent an objective parameter of uncontrolled disease ${ }^{28}$. In this study, $22.2 \%$ of children had positive responses after using $400 \mathrm{mcg}$ of salbutamol.

This study has some limitations, such as the cross-sectional design, the difficulty in correlating the sputum pattern with other variables, especially with the use of drugs such as inhaled or systemic corticosteroids. The collection of more than one sputum sample from the same patient, at different times, could confirm the 
predominant pattern and possible interferences of the medication.

In conclusion, this study found a predominance of eosinophilic profile in the sputum of stable asthmatic children, but it also showed that other cytological patterns may be present, especially in a population of severe asthmatics.

The study also proved the viability of sputum induction in children with asthma, representing a safe, effective and tolerant technique that would be valuable in investigating patients who require specialized care, contributing to the perspective of individualization. treatment.

\section{REFERENCES}

1. Cardoso TDA, Roncada C, Rodrigues E, Pinto LA, Jones MH, Stein RT, Pitrez, PM. Impacto da asma no Brasil : analise longitudinal de dados extraidos de um banco de dados governamental brasileiro. J Bras Pneumol 2017;43(3):163-168.

2. Papi A, Brightling C, Pedersen SE, Reddel HK. Asthma. Lancet 2018;391(10122):783-800.

3. Fitzpatrick AM, Moore WC. Severe asthma phenotypes - How should they guide evaluation and treatment? J Allergy Clin Immunol Pract [Internet] 2017;5(4):901-908. Available from: http://dx.doi.org/10.1016/j.jaip.2017.05.015.

4. Moore WC, Hastie AT, Li X, Li H, Busse WW, Jarjour NN, Wenzel SE, Peters SP, Meyer DA, Bleecker ER. Sputum neutrophil counts are associated with more severe asthma phenotypes using cluster analysis. J Allergy Clin Immunol 2014;133(6):1557-1563.

5. Guidelines for the diagnosis and management of asthma full report 2007. Children. 2007. National Asthma Education and Prevention Program, Third Expert Panel on the Diagnosis and Management of Asthma. Bethesda (MD). Report No.: 07-4051. Available from: https://www.ncbi.nlm.nih.gov/books/NBK7232/

6. Kartasamita CB, Rosmayudi O, Demedts M. Total serum IgE and eosinophil count in children with and without a history of asthma, wheezing, or atopy in an urban community in Indonesia. J Allergy Clin Immunol 1994;94(6 PART 1):981-988.

7. Pizzichini E, Pizzichini MMM, Efthimiadis A, Evans S, Morris MM, Squillace D, et al. Indices of airway inflammation in induced sputum: Reproducibility and validity of cell and fluid-phase measurements. Am J Respir Crit Care Med 1996;154(2):308-317.

8. Lex C, Payne DNR, Zacharasiewicz A, Li AM, Wilson NM, Hansel TT, et al. Sputum induction in children with difficult asthma: Safety, feasibility, and inflammatory cell pattern. Pediatr Pulmonol. 2005; 39:318-324.

9. Global initiative for asthma: GLOBAL STRATEGY FOR ASTHMA MANAGEMENT AND PREVENTION. Updated 2020. Available from: https://ginasthma.org/wpcontent/uploads/2020/06/GINA-2020-report_20_06_04-1-wms.pdf

10. Roxo JPF, Ponte EV, Ramos DCB, Pimentel L, D'Oliveira Junior A, Cruz AA. Validacao do Teste de Controle da Asma em portugues para uso no Brasil: validation for use in Brazil. J Bras Pneumol 2010;36(2):159-166.

11. Oliveira SG, Sarria EE, Roncada C, Stein RT, Pitrez PM, Mattiello R. Validation of the Brazilian version of the childhood asthma control test (c-ACT). Pediatr Pulmonol 2016;51(4):358-363.

12. Palomino ALM, Bussamra MHCF, Saraiva-Romanholo BM, Martins MA, Nunes M do PT, Rodrigues JC. Escarro induzido em criancas e adolescentes com asma: seguranca, aplicabilidade clinica e perfil de celulas inflamatorias em pacientes estaveis e durante exacerbacao. J Pediatr (Rio J) 2005;81(3):216-224.

13. Bush A. Pathophysiological mechanisms of asthma. Front Pediatr 2019;7:1-17.

14. Bossley CJ, Fleming L, Gupta A, Regamey N, Frith J, Oates T, et al. Pediatric severe asthma is characterized by eosinophilia and remodeling without TH2 cytokines. J Allergy Clin Immunol [Internet] 2012;129(4):974-982.e13. Available from: http://dx.doi.org/10.1016/j.jaci.2012.01.059

15. Loutsios C, Farahi N, Porter L, Lok LSC, Peters AM, Condliffe AM, et al. Biomarkers of eosinophilic inflammation in asthma. Expert Rev Respir Med 2014;8(2):143-150.

16. Hastie AT, Moore WC, Li H, Rector BM, Ortega VE, Pascual RM, et al. Biomarker 
surrogates do not accurately predict sputum eosinophil and neutrophil percentages in asthmatic subjects. J Allergy Clin Immunol [Internet] 2013;132(1):72-80.e12. Available from: http://dx.doi.org/10.1016/j.jaci.2013.03.044

17. Ullmann N, Bossley CJ, Fleming L, Silvestri M, Bush A, Saglani S. Blood eosinophil counts rarely reflect airway eosinophilia in children with severe asthma. Allergy Eur J Allergy Clin Immunol 2013;68(3):402406.

18. Fleming L, Tsartsali L, Wilson N, Regamey N, Bush A. Sputum inflammatory phenotypes are not stable in children with asthma. Thorax 2012;67(8):675-681.

19. Boulet LP. Effects of steroid therapy on inflammatory cell subtypes in asthma. Thorax 2010;65:374-376.

20. Eller MCN, Vergani KP, Saraiva-Romanholo BM, Antonangelo L, Leone C, Rodrigues JC. Can inflammatory markers in induced sputum be used to detect phenotypes and endotypes of pediatric severe therapy-resistant asthma? Pediatr Pulmonol 2018;53(9):1208-1217.

21. Luisi F, Pinto L araujo, Marostica L, Jones MH, Stein RT, Pitrez PM. Funcao pulmonar persistentemente reduzida em criancas e adolescentes com asma. J Bras Pneumol 2012;38(12):158-166.

22. Rodrigues AM, Roncada C, Santos G. Caracteristicas clinicas de criancas e adolescentes brasileiros com asma grave resistente a terapia. J Bras Pneumol 2015;41(12):343-350.

23. Meltzer EO. Allergic Rhinitis. Burden of illness, quality of life, comorbidities, and control. Immunol Allergy Clin North Am [Internet] 2016;36(2):235-248. Available from: http://dx.doi.org/10.1016/j.iac.2015.12.002

24. Esteves PC, Rosario Filho NA, Trippia SG, Caleffe LG. Sensibilizacao atopica em escolares e adultos de Curitiba, Parana. Rev Bras Alerg e Imunopatol 1999;22(5):156-160.

25. Silva EG da, Ribeiro JL, Campos MR de C. Perfil de sensibilizacao a alergenos prevalentes em clinica especializada de Catalao, Goias. Arq Asma, Alerg e Imunol 2017;1(3):299-304.

26. Calamita Z. Perfil de sensibilizacao a aeroalergenos e especies de acaros mais prevalentes na cidade de Marilia : dados preliminares. Bjai 2014;1(6):335-340.

27. Coverstone A, Bacharier LB, Fitzpatrick AM. Severe asthma in school-age children: Evaluation and phenotypic advances. Curr Allergy Asthma Rep 2015;15(5). doi: 10.1007/s11882-015-0521-5.

28. Galant SP, Morphew T, Newcomb RL, Hioe K, Guijon O, Liao O. The relationship of the bronchodilator response phenotype to poor asthma control in children with normal spirometry. J Pediatr [Internet] 2011;158(6):953-959.e1. Available from: http://dx.doi.org/10.1016/j.jpeds.2010.11.029.

\section{Hosted file}

TABLES_INDUCED SPUTUM.pdf available at https://authorea.com/users/342694/articles/507029evaluation-of-induced-sputum-cytology-in-asthmatic-children 